\title{
Bone marrow fibre content in acute myeloid leukaemia before and after treatment
}

\author{
ANWARUL ISLAM, DANIEL CATOVSKY, JOHN M GOLDMAN, DAVID AG GALTON \\ From the MRC Leukaemia Unit, Royal Postgraduate Medical School, Hammersmith Hospital, DuCane \\ Road, London W12 OHS
}

SUMMARY Bone marrow fibre content was studied in 34 patients with acute myeloid leukaemia at presentation and subsequently after chemotherapy and at complete remission. The findings indicate that: (1) some degree of marrow fibrosis is present in about one third of the patients with acute myeloid leukaemia at presentation; (2) effective antileukaemia treatment may result in reversal of marrow fibrosis; and (3) increase in marrow fibre content at diagnosis does not affect haemopoietic regeneration after treatment and achievement of complete remission.

Bone marrow trephine biopsy in patients with haematological malignancies has shown that focal or diffuse increases in marrow reticulin may be found in many of these conditions, including acute leukaemias. ${ }^{1-4}$ Kundel $e t a l^{2}$ reported that as many as $30 \%$ of patients with acute leukaemia, both lymphoblastic and myeloblastic, have a diffuse increase in marrow reticulin. A much higher incidence of marrow fibrosis has been reported by others ${ }^{5}$ in both these conditions. Patients with reticulin fibrosis of their marrows have been considered to have poorer prognoses than those without such increases. ${ }^{2}$

The present study was carried out on material from 34 patients with acute myeloid leukaemia treated with intensive chemotherapy. The frequency, extent, and type of fibrosis at the time of initial diagnosis, the effect of cytotoxic therapy on the marrow fibre content, and the effect of fibrosis on prognosis were assessed and the possibility of haemopoietic regeneration in the presence of severe marrow fibrosis was examined. The question of acute or malignant myelosclerosis as a distinct entity separate from acute leukaemia with marrow fibrosis was also considered.

\section{Material and methods}

Bone marrow trephine biopsies were obtained from 34 patients with acute myeloid leukaemia at diagnosis and at varying intervals during the course of intensive remission induction chemotherapy and after its completion. One to four specimens were obtained from each patient during the first eight weeks of observation. All patients in this group were

Accepted for publication 1 August 1984 treated with one or two courses of the RATE protocol (daunorubicin, cytosine arabinoside, 6-thioguanine, and epipodophyllotoxin) (VP16213). ${ }^{6}$ Initially, all the trephine biopsy specimens were obtained with the $11 \mathrm{G}$ (regular adult) Jamshidi needle from the posterior iliac crest and later some of the biopsies were obtained with a new bone marrow biopsy needle. ${ }^{7}$ The biopsies were then processed in methyl-methacrylate ${ }^{89}$ from which $3 \mu \mathrm{m}$ sections were cut, without decalcification, with a tungsten carbide knife in a Jung's high performance microtome (Autocut). Sections were softened in $96 \%$ ethanol and were then attached to gelatin coated slides by gentle brushing with a soft brush. The methacrylate was dissolved from the sections by immersion in benzene, and the sections were stained with May-Grunwald-Giemsa and Gomori's reticulin stain.

The bone marrow fibre content in each section was visually assessed and graded according to the scoring system described previously. ${ }^{10}$ The type of bone marrow fibre was mainly reticulin in grades 1 and 2 , a combination of reticulin and collagen in grade 3 , and mainly collagenous in grade 4 . No increase in marrow reticulin was recorded as grade 0 and any focal increase was recorded separately.

\section{Results}

Seventy one specimens from 34 patients were studied: 34 were obtained at diagnosis and 37 were obtained after chemotherapy and after complete remission.

The bone marrow fibre content at the time of initial diagnosis of acute myeloid leukaemia in 34 cases 

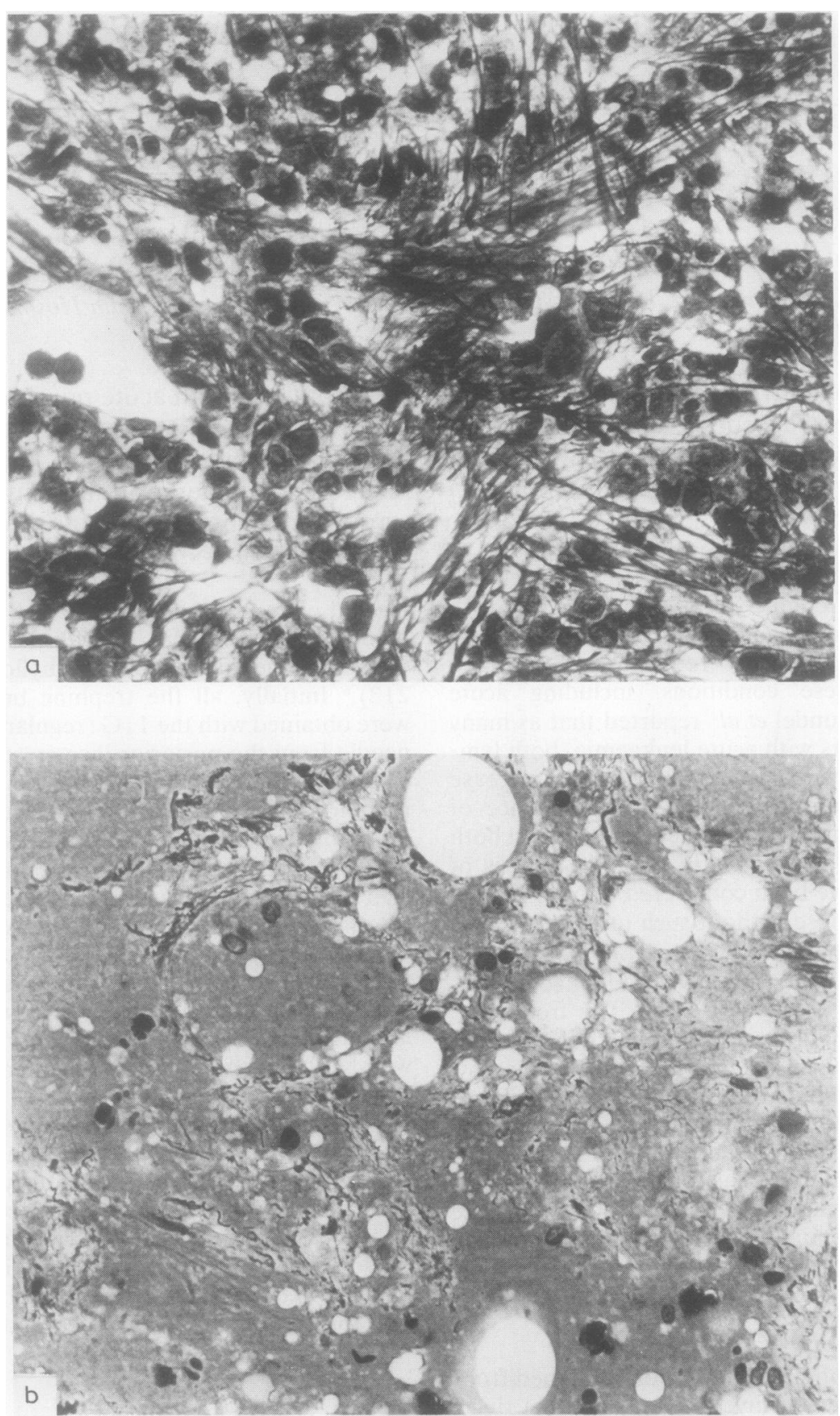


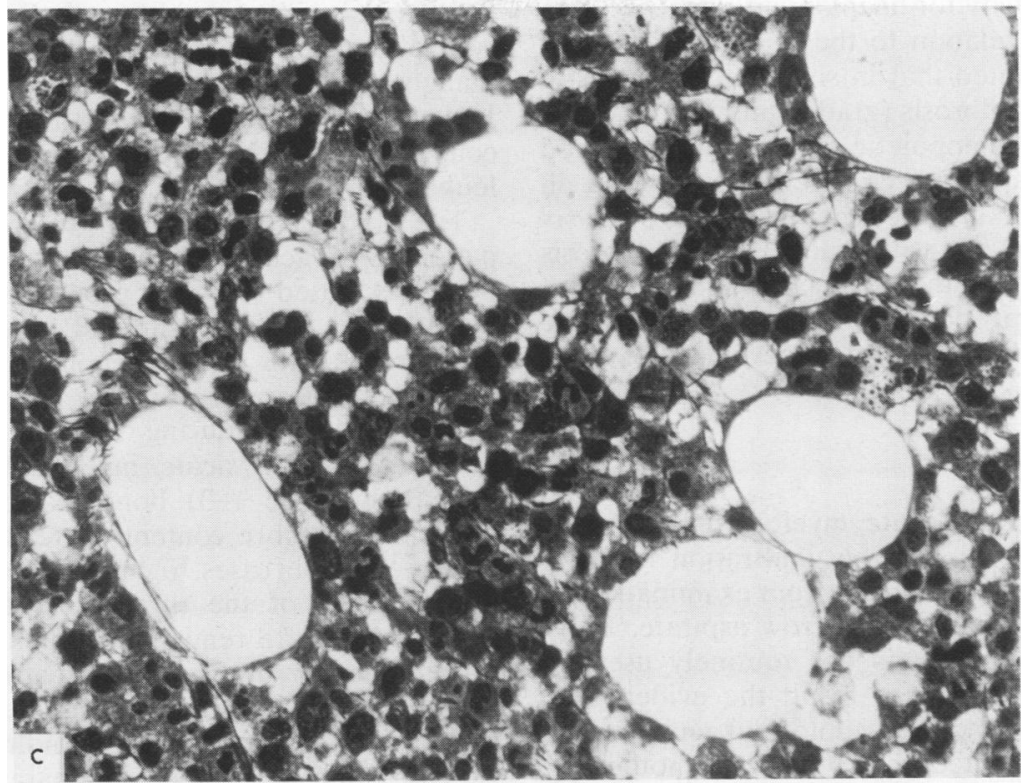

Bone marrow section from a case of acute myeloid leukaemia. (a) Showing considerable increase (grade 3) in bone marrow fibre content at diagnosis. Gomori's reticulin stain. Original magnification $\times 600$.

(b) Showing considerable reduction in the bone marrow fibre content after treatment. Gomori's reticulin stain. Original magnification $\times 600$.

(c) Complete remission showing good haemopoietic regeneration. A mild degree of marrow fibrosis can be seen. Gomori's reticulin stain. Original magnification $\times 600$.

Table 1 Bone marrow fibre content in patients with acute myeloid leukaemia at the time of initial diagnosis, after chemotherapy, and at complete remission

\begin{tabular}{|c|c|c|c|c|c|}
\hline \multirow{2}{*}{$\begin{array}{l}\text { Stages of the } \\
\text { disease }\end{array}$} & \multirow{2}{*}{$\begin{array}{l}\text { No of } \\
\text { cases } \\
\text { studied }\end{array}$} & \multicolumn{4}{|c|}{ Grade of fibrosis } \\
\hline & & 0 & 1 & 2 & 3 \\
\hline \multirow{3}{*}{$\begin{array}{l}\text { At diagnosis } \\
\text { After } \\
\text { chemotherapy } \\
\text { At complete } \\
\text { remission }\end{array}$} & 34 & $22(65 \%)$ & $9(26 \%)$ & 0 & $3(9 \%)$ \\
\hline & 23 & $18^{*}$ & 3 & 1 & 1 \\
\hline & 16 & 14 & 1 & 1 & 0 \\
\hline
\end{tabular}

${ }^{*}$ Five cases showed focal increase from grade $1(+)$ to grade 3 $(+++)$.

Table 2 Relation between the degree of marrow fibrosis and remission rate

\begin{tabular}{llll}
\hline Response to treatment & $\begin{array}{l}\text { No of } \\
\text { patients }\end{array}$ & \multicolumn{2}{l}{ Grade of fibrosis } \\
\cline { 2 - 4 } & & 0 & $1-3$ \\
\hline Complete remission & 16 & $11 / 17(65 \%)$ & $5 / 9(56 \%)$ \\
No remission & 10 & $6 / 17(35 \%)$ & $4 / 9(44 \%)$ \\
\hline
\end{tabular}

${ }^{*}$ Eight patients who died in the first four weeks, during induction treatment, due to unrelated causes were excluded. was as follows: grade 0 in $22(65 \%)$, grade 1 in nine, and grade 3 in three cases (Table 1). One of the nine cases with grade 1 fibrosis was classified as $M_{1}$, one as $M_{2}$, two as $M_{4}$, three as $M_{5}$, and one as $M_{6}$. Two of the three cases with grade 3 fibrosis were classified as $M_{1}$ and one as $M_{4}$ according to FAB criteria. When the initial degree of marrow fibrosis (at the time of diagnosis) was considered in relation to prognosis a slight excess in complete remission rates was noted in those with little or no fibrosis (grade 0 ) compared with those with grade 1-3 marrow fibrosis (Table 2). This difference, however, was not significant.

After intensive chemotherapy the bone marrow fibre content was decreased by at least one grade in five cases, including one of grade 3 fibrosis (Figure (a) and (b)). In 18 cases there was no change in the bone marrow fibre content. One of these 18 cases had grade 3 marrow fibrosis and did not show any change after two courses of chemotherapy. An increase (from grade 1 to grade 3 ) of a focal nature was seen in five cases, although the overall fibre content remained unchanged in all these cases except one which showed some reduction. 
When the capacity for haemopoietic regeneration was analysed in relation to the bone marrow fibre content, it was noted that in six of nine cases with increased marrow fibrosis (grade 1 in five and grade 3 in one) good haemopoietic regeneration occurred after chemotherapy with complete remission in all six of them. Haemopoietic regeneration in these six patients, including one with grade 3 marrow fibrosis (Figure (c)), suggests that increase in the bone marrow fibre content does not affect haemopoietic recovery after treatment and achievement of complete remission.

\section{Discussion}

The bone marrow in acute myeloid leukaemia is usually dominated by massive infiltration by blast cells and the diagnosis is made from examination of peripheral blood and bone marrow aspirate. Bone marrow trephine biopsy is not routinely used to establish a diagnosis. As a result the evidence of marrow fibrosis in acute myeloid leukaemia is not adequately documented, the effect of chemotherapy on the marrow fibre content remains unclear, and the concept that marrow fibrosis in acute myeloid leukaemia carries a poor prognosis is still upheld.

The present study shows that at least some increase in fibre content is present in $35 \%$ of the patients with acute myeloid leukaemia at presentation. The overall incidence of marrow fibrosis was lower in this group of patients than in those previously reported ${ }^{25}$ No particular morphological type of acute myeloid leukaemia in the FAB classification" ${ }^{11}$ had increased marrow fibrosis in comparison with the other types.

The pathogenesis of marrow fibrosis in patients with acute leukaemia is not clear, but it is generally considered to be reactive. ${ }^{12}$ Burston and Pinniger ${ }^{1}$ proposed that the increase in the bone marrow fibre content was a physiological response to increased haemopoietic activity. This theory has, however, been questioned by Sanerkin ${ }^{3}$ since highly cellular marrows may have a normal bone marrow fibre content. The present findings confirm the view of Sanerkin since $65 \%$ of the patients with acute myeloid leukaemia in this series had highly cellular bone marrows but normal fibre content.

The presence and importance of marrow fibrosis in malignant disorders of the blood and lymphoid tissue have become more widely recognised ${ }^{512-15}$ and have raised doubts about the validity of the distinction between malignant myelosclerosis and acute granulocytic leukaemia first proposed by Lewis and Szur. ${ }^{16}$ In the present study three patients presented with features similar to those of malignant myelosclerosis and showed considerable (grade 3 ) marrow fibrosis and circulating blast cells. The most frequent type of leukaemia associated with the syndrome of malignant myelosclerosis is megakaryoblastic leukaemia, ${ }^{17}$ but as has been shown in this study it could also be seen in other types of acute myeloid leukaemia.

The finding of increased marrow reticulin in patients with acute leukaemia has been regarded as being associated with poor prognosis, attributable to the persistence of reticulin and consequent possible interference with normal repopulation of the marrow after therapeutic aplasia. ${ }^{2}$ Cytotoxic therapy was successful in inducing complete remission in six of nine cases of acute myeloid leukaemia with increased (grade 1-3) bone marrow fibrosis; the bone marrow fibre content decreased concurrently in three of the cases, including one with grade 3 fibrosis. Two of the three patients who did not achieve complete remission also showed reduction in the bone marrow fibre content after treatment but they failed to regenerate adequately and died of intercurrent infection. These findings confirm the view of Hann et $a l^{18}$ and Manoharan $e t a^{5}$ that the occurrence of marrow fibrosis does not necessarily change the overall prognosis of patients with acute leukaemia and that effective treatment may result in resolution of the increased marrow reticulin and thus help the repopulation of the bone marrow by normal regenerating haemopoietic cells. Reversal of marrow fibrosis has also been reported ${ }^{19}$ in acute megakaryoblastic leukaemia after remission induction and consolidation chemotherapy followed by bone marrow transplantation.

\section{References}

' Burston J, Pinniger JL. The reticulin content of bone marrow in haematological disorders. Br J Haematol 1963;9:172-84.

${ }^{2}$ Kundel DW, Brecher G, Bodey GP, Brittin GM. Reticulin fibrosis and bone infarction in acute leukemia. Implications for prognosis. Blood 1964;23:526-44.

${ }^{3}$ Sanerkin NG. Stromal changes in leukaemic and related bone marrow proliferations. J Clin Pathol 1964;17:541-7.

${ }^{4}$ Amaki I, Takizawa Y, Higo O, Ueki Y, Hagihara T. Serial observations of the fibrous tissue in the bone marrow of haematological disorders. Tohoku Journal of Experimental Medicine 1968;96:379-91.

's Manoharan A, Horsley R, Pitney WR. The reticulin content of bone marrow in acute leukemia in adults. $\mathrm{Br} J$ Haematol 1979;43:185-90.

- Goldman JM, Catovsky D, Hows J. Cryopreserved peripheral blood cells functioning as autografts in patients with chronic granulocytic leukaemia in transformation. $\mathrm{Br}$ Med J 1979;: $1310-3$.

7 Islam A. A new bone marrow biopsy needle with core securing device. J Clin Pathol 1982;35:359-64.

${ }^{8}$ Burkhardt R. Colour atlas of clinical histopathology. New York: Springer-Verlag, 1971.

' Islam A. Bone marrow structure in human leukaemia: a histological study by plastic embedding technique. London: London University, 1982. PhD Thesis. 
${ }^{10}$ Islam A, Catovsky D, Goldman JM, Galton DAG. Histological study of bone marrow in chronic granulocytic leukaemia in blast transformation. II. Bone marrow fibre content before and after autografting. Histopathology 1981;5:491-8.

" Bennett JM, Catovsky D, Daniel MT, Flandrin G, Galton DAG, Gralnick HR, Sultan C. Proposal for the classification of the acute leukaemias. Br J Haematol 1976;33:451-8.

12 Zittoun R, Diebold J, Gorin NC. Leucemies aigues avec myelofibrose. Nouvelle Revue Francaise d'Hematologie 1972;12:229-40.

${ }^{13}$ Neis BA, Kundel DW, Thomas LB, Freireich EJ. Leukopenia, bone pain, and bone necrosis in patients with acute leukemia. Ann Intern Med 1965;62:698-705.

${ }_{14}$ Devred C, Diebold J. La myelofibrose au course des hemopathies: valeur diagnostique et prognostique. Sem Hop Paris 1974; 50:1625-34.

is Diebold J. Myelofibrose et reseau fibrillaire de soutien de la moelle ossense hematopoietique. Sem Hop Paris 1974;50:1619-24.
${ }^{16}$ Lewis SM, Sxur L. Malignant myelosclerosis. $\mathrm{Br}$ Med J 1963;ii:472-7.

17 Bain BJ, Catovsky D, O'Brien M, Spiers ASD, Richards HGH. Megakaryoblastic leukaemia presenting as acute myelofibrosis - a study of four cases with the platelet peroxidase reaction. Blood 1981;58:206-13.

${ }^{18}$ Hann IM, Evans DIK, Marsden HB, Morris Jones P. Bone marrow fibrosis in acute lymphoblastic leukaemia of childhood. $J$ Clin Pathol 1978;31:313-5.

19 Mehta AB, Baughan AS, Catovsky D, Goldman JM, Johnson SA, Galton DAG. Reversal of marrow fibrosis in acute megakaryoblastic leukaemia after remission induction and consolidation chemotherapy followed by bone marrow transplantation. Br J Haematol 1983;53:445-9.

Requests for reprints to: Dr Anwarul Islam, Leukemia Service, Roswell Park Memorial Institute, 666 Elm Street, Buffalo, NY 14263, USA. 